\title{
A AÇÃO CULTURAL NAS PRÁTICAS DE FORMAÇÃO DOS PROFISSIONAIS DA EDUCAÇÃO MUSICAL: DA EDUCAÇÃO POPULAR AOS MOVIMENTOS SOCIAIS
}

\author{
Márcio Penna Corte Real \\ Oscar Daniel Morales \\ Daniela Morales \\ Paulo Thies Lopes \\ Sólon Mendes
}

\section{INTRODUÇÃO}

Esta análise parte da experiência dos autores trabalhando com classes de educação musical para adolescentes no espaço da comunidade do Lar Metodista de Santa Maria e na organização de círculos de cultura musical no âmbito do Projeto CUIA. Este último é um projeto firmado em parceria entre o INCRA, UFSM e o MST - Movimento dos Trabalhadores Rurais Sem Terra.

Em ambos os espaços, temos discutido, na prática educacional, a questão da compreensão da realidade sócio-cultural dos sujeitos envolvidos como necessária na organização de um programa educativo de formação de professores. Assim, temos vivido o que denominamos círculo de cultura musical, representando a possibilidade de que o ato educativo, aqui balizado pelo fundamento dialógico da sugestão freireana e da investigação-ação educacional, seja configurado como investigação e ação sobre os temas da cultura dos grupos organizados.

Almejamos, assim, o redimensionamento das práticas educacionais, e, sobretudo, buscamos um enfoque crítico para a leitura de mundo de educadores-educandos e educandos-educadores. Pontuamos algumas das ações implementadas em pesquisa por nós desenvolvida em curso de Mestrado em Educação — vinculada ao PPGE/CE/UFSM - sobre o tema A Cultura do Negro na Educação Musical para melhorar a sua situação sócio-cultural via Investigação-ação Educacional Emancipatória. O objetivo deste trabalho tem sido a problematização da cultura negra na classe referida, procedendo, assim, no diálogo sobre elementos musicais que historicamente tiveram a contribuição dos negros na sua origem e que são contextualizados e problematizados, respeitando, para isso, a leitura de mundo dos educandos.

Concluímos argumentando sobre a pontualidade de tomarmos a cultura do educandos como ponto de partida do ato educativo. Todavia, entendo a cultura não como um patrimônio de grupos isolados, mas de seres humanos que se completam como tal nas suas relações socais.

\section{O ENTENDIMENTO SOBRE A CULTURA E A AÇÃO CULTURAL}

A compreensão do conceito de cultura é necessária, ainda mais, quando pretende-se que aquela se volte para o meio educacional. A discussão sobre a 
questão da cultura tem sido bastante ampla. Muitos autores dedicaram trabalhos exclusivamente para tentar elucidar o seu conceito e o uso que lhe vêm sendo dado, como, por exemplo, o trabalho de CUCHE (1999), que, todavia, é um educador que nos mostra uma acepção um tanto quanto pontual para o conceito de cultura. Estamos falando de FREIRE (1981), que discorre sobre o tema com bastante clareza, colocando

A cultura como acrescentamento que o homem faz ao mundo que não fez. A cultura como o resultado do seu trabalho. Do seu esforço criador e recriador. O sentido transcendental de suas relações. A dimensão humanista da cultura. A cultura como aquisição sistemática da experiência humana. Como uma incorporação, por isso crítica e criadora, e não como uma justaposição de informes ou prescrições "doadas".( p.109).

Nesta acepção, o conceito de cultura é tão amplo quanto mostra o seu caráter dinâmico. E nos mostra também o lado transformador que caracteriza o ser humano através do seu "esforço criador e recriador" (Ibid. p.109).

A cultura, pois, é a própria atividade humana, a configuração das suas relações e o retrato do seu ambiente que se faz num tempo que é concreto e histórico. Daí que "o problema que nos apresenta [enquanto educadores] é o de encontrar, em cada realidade histórica, os caminhos de ida e volta entre o desvelamento da realidade e prática dirigida no sentido de sua transformação.(FREIRE 1982, p.60).

Desvelar a realidade, então, é uma tarefa que no campo das práticas educativas implica que "que a informação seja sempre precedida e associada à problematização do objeto em torno de cujo conhecimento dá esta ou aquela informação."(Ibid.54).

A problematização quando vinculada a evidenciar as contradições da realidade está colocada em começar-se a fazer a ação cultural para a libertação. "Implicando na inserção crítica na realidade [...] [e] se caracteriza pelo diálogo "como selo" do ato do conhecimento."(FREIRE 1982, p.81). Então que a ação cultural para a libertação só seja possível de ser concebida num espaço onde educadores e educandos dialoguem a partir da sua realidade, que é cultural e, talvez por isso, histórica. Parafraseando FREIRE (1981), podemos dizer que o diálogo na ação cultural para a libertação implica os seres humanos estarem sempre a par da sua responsabilidade política e social. Por isso, a criticam inicialmente com vistas à transformação de suas contradições.

A ação cultural para a libertação, por fim, não é tão somente a construção do processo educativo tendo "respeito a cultura e a identidade cultural do educando." (FREIRE 1996, p.46). "A ação cultural para a libertação é antes a própria reivindicação por uma educação, que por ser educação haveria de ser corajosa, propondo [ao homem] a reflexão sobre si mesmo, sobre o seu tempo, sobre suas responsabilidades "(FREIRE 1981, p.59).

\section{A INVESTIGAÇÃO-AÇÃO COMO AÇÃO CULTURAL}


A concepção da investigação-ação educacional caracteriza-se por ser problematizadora. E busca transformar dogmas, agregando a matriz freireana, através de "um esforço comum de consciência de realidade e de autoconsciência que a inscreve como ponto de partida do processo educativo e ação cultural de caráter libertador." (FREIRE, 1987 p. 99-100). Sendo assim, a investigação-ação emancipatória é concebida na prática educativa, com a colaboração do grupo de educadores-educandos inseridos em "situações reais concretas" (GRABAUSKA, 1999 p. 1).

Objetiva-se desta formar chegar a transformar as relações sociais que perpetuam o sistema de submissão cultural. Tendo em vista que:

Para transformar a realidade, visando a emancipação, é preciso ousar, desafiar as concepções dominantes, as quais perpetuam a miséria, a injustiça e a desigualdade. Nesse sentido, uma ação educacional que pretende avançar para além da racionalidade técnica, não pode limitar-se a olhar para relação educação e sociedade de forma não problemática, como se a escola estivesse aí apenas para transmitir saberes acumulados e formar mão-de-obra "qualificada". (GRABAUSKA e DE BASTOS 1999, p. 9)

Em outras palavras, entendemos que não podemos ficar inertes aos problemas que surgem no meio das praticas educativas; antes, é preciso buscarmos soluções, sabendo-se, que a educação não é simples reprodução técnica de conhecimentos.

\section{NOSSAS AÇÕES}

Nossa preocupação temática é no sentido de problematizar as produções musicais em contextos como das atividades culturais organizadas com os monitores do projeto CUIA e com os educandos do Lar Metodista, ambos citados anteriormente.

Nesses contextos destacamos as oficinas de educação musical realizadas semanalmente com os educandos do Lar Metodista, onde o objetivo principal é de trabalhar elementos musicais que, através de sua origem histórica na cultura negra, tem-nos permitido a problematização da própria realidade dos educandos.

Utilizamos recursos como canções e ritmos característicos da cultura negra através do fundamento dialógico conforme FREIRE(1981, 1982, 1987, 1996), no sentido do desvelamento dos temas que nos orientam. Destacamos outro momento de nossas atuações, por ocasião da realização da atividade que, inicialmente, denominávamos de concertos didáticos e que, mais tarde, passamos a conceituar como círculo de cultura musical. Reivindicando, assim, o "circulo de cultura", na acepção freireana (FREIRE 1981), como o lugar em que os homens se encontram mediados pelo ato de conhecimento da realidade, no nosso caso, através da música como um elemento a colaborar com a educação. 
Trabalhamos, então, em círculos de cultura musical onde todas as pessoas são participantes ativos do fazer musical. Foi o caso, por exemplo, da atividade cultural realizada na segunda capacitação do projeto CUIA, onde realizamos, com um grupo formado por um professor do departamento de música do CAL/UFSM, três acadêmicos do curso de licenciatura em música da UFSM e um mestrando em educação da mesma instituição, um círculo de cultura musical.

Nesta atividade, a nossa preocupação foi de que fizéssemos música não para os cinqüenta monitores e os dez coordenadores locais do referido projeto, mas sim, fazermos música com eles. Até no sentido de desmitificarmos juntos a idéia que se tem, em geral, da prática musical como atividade reservada para poucos capazes de fazê-lo.

Inicialmente apresentamos algumas músicas executadas pelo grupo de educadores e logo a seguir partimos para a organização do que seria um "concerto musical", onde todos participariam ativamente. O resultado foi que, ao final deste trabalho, conseguimos realizar, coletivamente, uma performance musical com aproximadamente setenta pessoas. Essa atividade foi a primeira de uma série que vimos realizando com os educadores do projeto CUIA, com o objetivo de dialogar criticamente sobre a sua produção cultural através das músicas de protesto do MST, em contraposição com a indústria cultural.

\section{A CONCEPÇÃO DO CIRCULO DE CULTURA MUSICAL}

A questão do circulo de cultura, ao qual adicionamos "musical", nos remete à acepção freireana quando coloca que a opinião crítica "é um dos princípios essenciais para a estruturação do círculo de cultura, unidade de ensino que substitui a 'escola', autoritária por estrutura e tradição. Busca-se o círculo de cultura, peça fundamental nos movimentos de educação popular."(FREIRE 1981, p.5).

Daí que o círculo de cultura é o lugar onde se trava a relação do ser humano mediado pela suas relações "homens-mundo."(Ibid.1981). Relações estas que são problematizadas. O círculo de cultura tem, pois, o sentido de reivindicar o homem como um ser de existência histórica e cultural e, por isso, ser de historicidade

\section{CONSIDERAÇÕES SOBRE A CULTURA NA PRÁTICA EDUCATIVA}

Ao nos encaminhamos para o desfecho desta análise, gostaríamos de fazê-lo tomando duas considerações. Uma é a de que procuramos discutir, ao longo desta análise, a questão da "cultura como um elemento que possa colaborar com o processo educativo; ainda mais quando configurado como investigação e ação com vista da emancipação dos sujeitos."(CORTE REAL, 2000)

Todavia, o que destacamos é que a cultura(negra) não deve ser vista como um mero determinante de grupo ou de classe social, mas sim como um ponto de partida do fazer educacional, como parafraseamos de FREIRE (1996). 
Outra consideração é a de que a questão da cultura, enquanto elemento do poder de transformação que o humano tem, significa a possibilidade de o compreendermos em relação ao seu mundo; sempre, então, no aspecto problemático da realidade em que vive. Repita-se, então: realidade esta que é "histórica e cultural". FREIRE (1996) E, ainda - buscamos o apontamento do mesmo autor — realidade que, permita-se reiterarmos, por ser histórico-cultural nos coloca o presente e o "futuro sempre como problemáticos, mas nunca como inexoráveis." (Ibid. 1996)

\section{BIBLIOGRAFIA}

DE BASTOS e outros. "Ação cultural para a libertação: a questão da cultura na pedagogia do oprimido". Estudos Leopoldenses. Série Educação, Vol.3, n.4. 1999.

CORTE REAL, Márcio P. e outros. "A questão da cultura negra na educação musical: o espaço da cultura na investigação-ação educacional". In: Atas da VI Escola de Verão de Investigação-ação Educacional. Santa Maria: PPGE/CE/UFSM. 2000

CUCHE, Denis. A noção da cultura nas ciências sociais. Bauru: Edusc, 1999.

FREIRE, Paulo. Pedagogia do oprimido. 17 ed. São Paulo: Paz e Terra, 1987.

. Ação cultural para a liberdade e outros escritos. 6 ed. Rio de Janeiro:

Paz e Terra, 1982. $\overline{1981 .}$

Educação como prática da liberdade. 12 ed. Rio de Janeiro: Paz e Terra,

. Pedagogia da autonomia: saberes necessários à prática educativa. 12 ed. Rio de Janeiro: Paz e Terra, 1996.

GRABAUSKA, C. DE BASTOS, F. "Investigação-ação educacional: possibilidades críticas e emancipatórias na prática educativa". In: HEURESIS, Vol 1 n2, 1998. 